\title{
Effect of decompressive laparotomy on organ function in patients with abdominal compartment syndrome: a systematic review and meta-analysis
}

\author{
Lana Van Damme ${ }^{1}$ and Jan J. De Waele ${ }^{2^{*}}$ (1)
}

\begin{abstract}
Background: Decompressive laparotomy has been advised as potential treatment for abdominal compartment syndrome (ACS) when medical management fails; yet, the effect on parameters of organ function differs markedly in the published literature. In this study, we sought to investigate the effect of decompressive laparotomy on intraabdominal pressure and organ function in critically ill adult and pediatric patients with ACS, specifically focusing on hemodynamic, respiratory, and kidney function and outcome.

Methods: A systematic review and meta-analysis of the literature was performed. Articles reporting data on intraabdominal pressure (IAP), hemodynamic (mean arterial pressures [MAP], central venous pressure [CVP], cardiac index $[\mathrm{Cl}]$, heart rate $[\mathrm{HR}]$, systemic vascular resistance index [SVRI] and/or pulmonary capillary wedge pressure $[P C W P]$ ), respiratory (positive end-expiratory pressure $[P E E P]$, peak inspiratory pressure $[P I P]$ and/or ratio of partial pressure arterial oxygen and fraction of inspired oxygen [P/F ratio]), and/or urinary output (UO) following decompressive laparotomy were analyzed.
\end{abstract}

Results: A total of 15 articles were included; 3 included children only (aged 18 years or younger). Of the 286 patients who were included, $49.7 \%$ had primary ACS. The baseline mean IAP in adults decreased with an average of $18.2 \pm 6.5 \mathrm{mmHg}$ following decompression, from $31.7 \pm 6.4 \mathrm{mmHg}$ to $13.5 \pm 3.0 \mathrm{mmHg}$. There was a decrease in HR $(12.2 \pm 9.5$ beats $/ \mathrm{min} ; p=0.04)$, CVP $(4.6 \pm 2.3 \mathrm{mmHg} ; p=0.022)$, PCWP $(5.8 \pm 2.3 \mathrm{mmHg} ; p=0.029)$, and PIP $(10.1 \pm$ $\left.3.9 \mathrm{CmH}_{2} \mathrm{O} ; p<0.001\right)$ and a mean increase in $\mathrm{P} / \mathrm{F}$ ratio $(70.4 \pm 49.4 ; p<0.001)$ and $\mathrm{UO}(95.3 \pm 105.3 \mathrm{ml} / \mathrm{h} ; p<0.001)$. In children, there was a significant increase in MAP $(20.0 \pm 2.3 \mathrm{mmHg} ; p=0.006), \mathrm{P} / \mathrm{F}$ ratio $(238.2 ; p<0.001)$, and UO $(2.88 \pm 0.64 \mathrm{ml} / \mathrm{kg} / \mathrm{h} ; p<0.001)$ and a decrease in CVP $(7 \mathrm{mmHg} ; p=0.016)$ and PIP $\left(9.9 \mathrm{cmH}_{2} \mathrm{O} ; p=0.002\right)$. The overall mortality rate was $49.7 \%$ in adults and $60.8 \%$ in children following decompressive laparotomy.

Conclusions: Decompressive laparotomy resulted in a significantly lower IAP and had beneficial effects on hemodynamic, respiratory, and renal parameters. Mortality after decompressive laparotomy remains high in both adults and children.

Keywords: Intensive care, Abdominal compartment syndrome, Decompressive laparotomy, Multiple organ failure, Hemodynamic recovery, Respiratory recovery, Kidney recovery, Mortality rate

\footnotetext{
* Correspondence: jan.dewaele@ugent.be

${ }^{2}$ Department of Critical Care Medicine, Ghent University Hospital, C.

Heymanslaan 10, 9000 Ghent, Belgium

Full list of author information is available at the end of the article
}

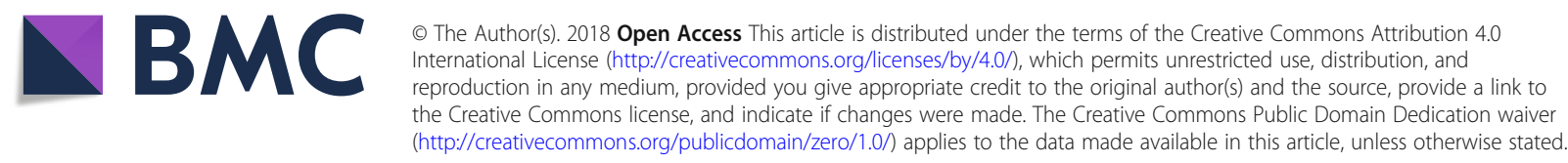




\section{Background}

Abdominal compartment syndrome (ACS) is defined by an intra-abdominal pressure (IAP) of $20 \mathrm{mmHg}$ or higher that is accompanied by newly developed organ dysfunction [1]. Although the first cases of ACS were described decades ago, interest has recently increased exponentially. Nevertheless, a recent survey demonstrated that knowledge among physicians is still suboptimal toward clinical management and awareness of ACS [2].

There is a wide range in the incidence of ACS in intensive care unit (ICU) patients, with patients in surgical ICUs more likely to develop ACS. Incidence rates of intra-abdominal hypertension (IAH) and ACS upon admission to the ICU are reported to be around $27.7 \%$ and $2.7 \%$, respectively $[3,4]$. The prevalence of ACS is between $4.2 \%$ and $14 \%$ in patients admitted to the ICU after trauma; in general ICUs, it is estimated to be around $1 \%$. With increasing insight into the risk factors for ACS, the introduction of guidelines, and the availability of strategies to limit progression from IAH to ACS, ACS seems to be decreasing in most ICUs $[5,6]$.

As in other compartment syndromes, surgical decompression has been considered the definitive therapy for ACS for a long time, particularly in primary ACS. In case of secondary ACS, surgical intervention may no longer be the treatment of choice. The IAH/ACS management algorithm, as developed by WSACS (The Abdominal Compartment Society, formerly known as the World Society of the Abdominal Compartment Syndrome), was recently updated and recommends medical treatment options to reduce IAP before surgical decompression is needed $[7,8]$. The cornerstone of medical management in patients with IAH (defined as IAP $\geq 12 \mathrm{mmHg}$ ) is perfusion support and optimized fluid management, with several noninvasive methods used to reduce IAP, such as nasogastric decompression or percutaneous drainage of fluid collections. Only when these noninvasive medical treatment options fail to lower the IAP and organ failure persists is decompressive laparotomy recommended [1, 9-11].

The effect of decompressive laparotomy on organ function in patients with ACS has been poorly described. Because mortality rates remain as high as $49 \%$ even after decompression [12], further investigation is needed into the use of decompressive laparotomy to understand who could benefit the most. From a mechanistic point of view, for example, patients with decreased abdominal wall compliance would benefit the most, but this has been largely ignored. Our goal in this study was to investigate the effect of decompressive laparotomy on organ function, particularly on hemodynamics and respiratory and renal function, in a broad ICU population.

\section{Methods}

\section{Search strategy}

The literature was reviewed for studies reporting on the effect of decompressive laparotomy in patients with ACS published between 1995 and September 2017. The search terms ("abdominal compartment syndrome" or "intra-abdominal hypertension" or "intra-abdominal pressure" and "decompression" or "decompressive surgery" or "decompressive laparotomy") were used to search three databases (MEDLINE, Embase, and Web of Science). Restrictions were applied to the search query. To minimize publication bias, case reports were excluded, as were case series or reviews describing fewer than five patients. In addition, animal studies were not considered. The search was limited to literature published in the English, French, German, Dutch, and Spanish languages. The bibliographies of the included articles were examined for relevant publications that might have been overlooked otherwise.

\section{Inclusion and exclusion criteria}

Eligible studies were assessed on the basis of predefined inclusion and exclusion criteria. Studies that described adult and pediatric patients who developed ACS and required decompressive laparotomy were included in the analysis.

Studies were included only if they reported the IAP at least before the procedure, or if they defined ACS, in addition to patient outcome for every patient who underwent decompressive laparotomy. Hemodynamic (blood pressure [BP], heart rate [HR], systemic vascular resistance index $[\mathrm{SVRI}]$, cardiac index $[\mathrm{CI}]$, pulmonary capillary wedge pressure [PCWP], and/or central venous pressure $[\mathrm{CVP}]$ ), renal (urinary output $[\mathrm{UO}]$ ), and/or respiratory (ratio of partial pressure arterial oxygen and fraction of inspired oxygen $[\mathrm{P} / \mathrm{F}$ ratio], peak expiratory end pressure $[\mathrm{PEEP}]$, and/or peak inspiratory pressure [PIP]) parameters were required to be reported to measure the effect on organ dysfunction. Patients who underwent decompressive laparotomy needed to be clearly identified, and the data of these patients had to be discussed separately. The time frame of measuring these parameters had to be less than 72 hours after the intervention.

Decompressive laparotomy was defined as a vertical, midline, full-thickness abdominal incision aimed at reducing the IAP. This may or may not have been followed by a temporary abdominal closure. Other decompression techniques, such as subcutaneous fasciotomy or subcostal laparotomy, were not included.

\section{Data extraction and outcome measures}

Baseline characteristics of the patients as well as of the studies were extracted. These included first author; year 
of publication; number of patients; study design; and basic patient characteristics, such as age, gender, and cause of ACS. Studies were categorized according to whether the WSACS definition [1] was used in the diagnosis of ACS. Each article was then categorized according to which type of ACS it described, namely primary, secondary, or combined. Studies reporting pediatric patients were analyzed separately. Hemodynamic, renal, and/or respiratory parameters were extracted and analyzed.

\section{Statistical analysis}

For statistical analysis, the Comprehensive Meta-Analysis software package (Biostat, Englewood, NJ, USA) was used. The outcome parameters retrieved from the studies (described as mean, SD, and sample size) were entered into the program to calculate the standardized mean difference (SMD) of each parameter as well as the $p$ value. When articles described median and range, an estimation of mean and SD was made using the formula described by Hozo et al. [13]. Heterogeneity across studies was evaluated using Cochran's $Q$ statistic. A random effects model was used when heterogeneity was present, as suggested by DerSimonian and Laird, to reduce bias [14]. A $p$ value $<0.1$ for the Cochran's $Q$ statistic was considered to represent significant between-study heterogeneity. The $p$ value was considered statistically significant when this was $<0.05$. Hedges' $g$ was used to examine the SMD, because the $p$ value provides information about only the presence of an effect and not the size of the effect. The following cutoffs were considered to estimate the effect size of the intervention on the reported parameter: $0.2-0.5$, a small effect size; $0.5-0.8$, a medium effect size; and $>0.8$, a large effect size.

\section{Quality assessment}

A funnel plot was used to assess the presence of publication bias visually and was quantified by the Egger test. The threshold for bias was a $p$ value $<0.10$. Two validated checklists were conducted to assess the methodological quality of all included studies. First, the methodological index for nonrandomized studies (MINORS) [15] was used, which contained a checklist consisting of 8 criteria for noncomparative studies and 12 items for comparative studies. Downs and Black [16] drafted a checklist for not only nonrandomized but also randomized studies. With this list, 27 items were verified to assess the quality of the studies. To facilitate assessment, combining both studies $[32,33]$, each score was converted to a 0-10 scale, and an average score was then calculated. The lower the score, the higher the risk of bias, and vice versa.

\section{Results}

Study flow and characteristics

The literature search identified 184 articles, which were retrieved for further evaluation. Of these, 156 studies were excluded on the basis of title and abstract, and of the 28 full-text articles reviewed, 13 were excluded because the necessary information was lacking. Ultimately, 15 articles were included in the analysis. A summary of the study identification and selection flow is provided in Fig. 1.

Overall, 286 patients with 292 ACS episodes were included in the analysis. Three articles reported on patients aged 18 years or younger. Of the 286 patients who were included, $49.7 \%$ had primary ACS. The study characteristics are described in Table 1 . Seven of the included articles described prospective observational cohort studies, six reported retrospective observational cohort studies, one was a case series, and another one combined both prospective and retrospective data.

\section{Publication bias and sensitivity analysis}

The study funnel plot showed a quite symmetrical dispersion of the studies, as can be seen in Fig. 2. When the results were quantified through an Egger's regression intercept, a $p$ value (one-sided) of 0.33 was calculated. The methodological quality of the included studies, based on the validated checklists, showed two studies with low scores, six with moderate scores, another five with moderate to high scores, and two with high scores. The scoring of the assessment is provided in Table 2.

\section{Effect of decompressive laparotomy in adults Effect of decompressive laparotomy on IAP in adults}

The effect of decompressive laparotomy on IAP was available in 8 of 15 studies and is summarized in Fig. 3. The baseline mean IAP was $31.7 \mathrm{mmHg}$ and ranged from $23 \mathrm{mmHg}$ to $43.4 \mathrm{mmHg}$. Following decompression, the IAP decreased to an average of $13.5 \mathrm{mmHg}$, varying between 11 and $17 \mathrm{mmHg}$.

\section{Effect on hemodynamics, the respiratory system, and kidney function in adults}

The effect on the different organ systems is summarized in Table 3. Regarding hemodynamics, the largest SMD (1.117) was observed for PCWP, where there was a mean overall decrease of $5.8 \pm 5 \mathrm{mmHg}$ after decompressive laparotomy; the CVP decreased by $4.6 \pm 2.3 \mathrm{mmHg}$. The overall effect on respiratory function in adults was available in 9 of 12 studies. For the PIP, there was a mean decrease of $10.1 \pm 3.9 \mathrm{cmH}_{2} \mathrm{O}$ following decompressive laparotomy. The $\mathrm{P} / \mathrm{F}$ ratio increased with $70.4 \pm$ $49.4 \mathrm{mmHg}$ postdecompression. The effect on UO was reported in 197 patients; an overall mean increase of $95.3 \pm$ $105.3 \mathrm{ml} / \mathrm{h}$ was reported after decompressive laparotomy.

\section{Effect of decompressive laparotomy in patients with grade III/IV and grade IV ACS}

Five studies described patients with grades III and IV ACS. In these patients, the mean baseline IAP was 


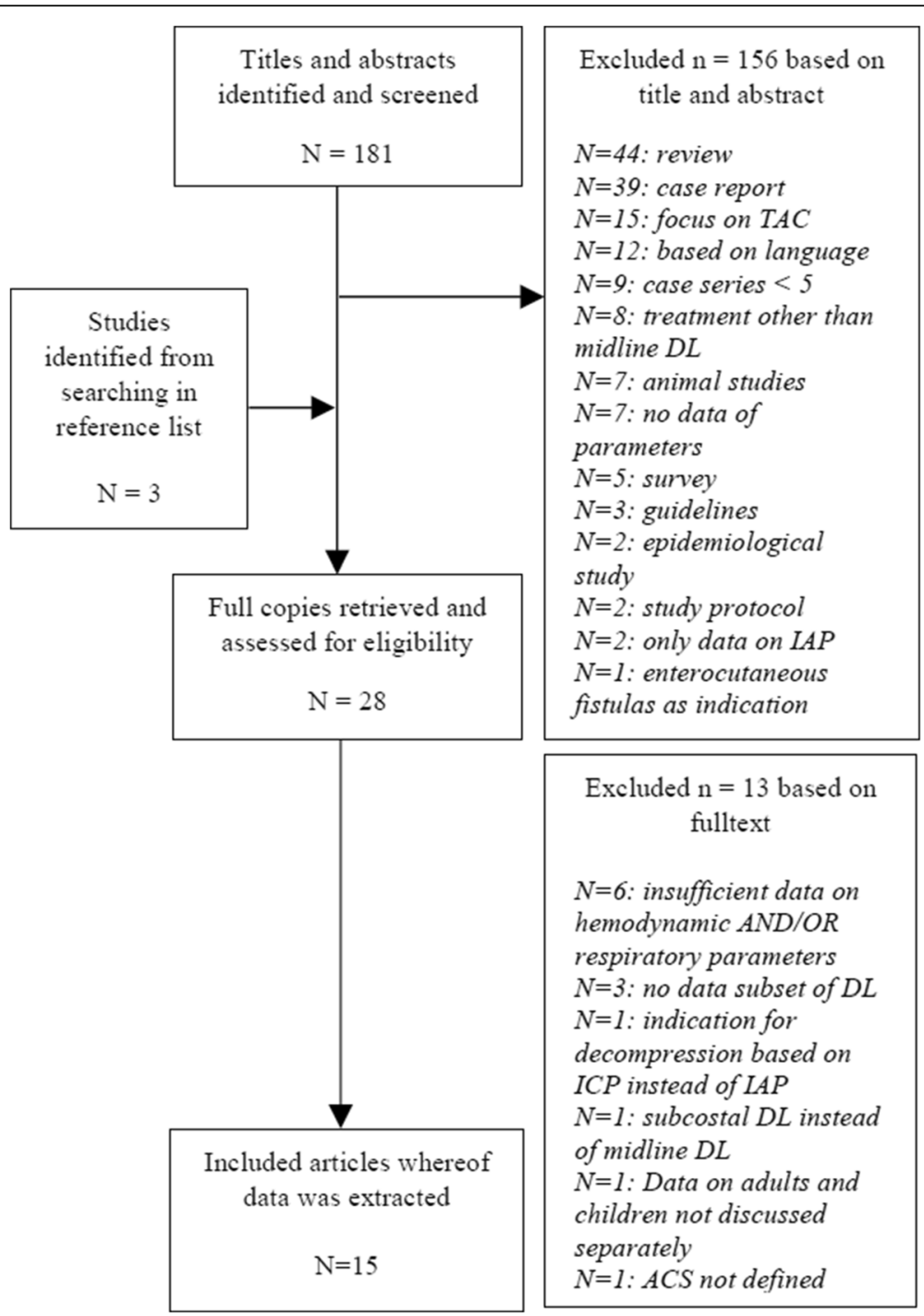

Fig. 1 Study selection flowchart

$29 \mathrm{mmHg}$ (23-36 $\mathrm{mmHg})$. The mean postoperative IAP was $12.7 \mathrm{mmHg}(8-15 \mathrm{mmHg})$. For the articles reporting grade IV ACS, the mean preoperative IAP was $36.1 \mathrm{mmHg}(30.2-42 \mathrm{mmHg})$. After decompressive laparotomy, the IAP decreased to a mean value of $14.7 \mathrm{mmHg}(11.1-17 \mathrm{mmHg})$.

The effect on hemodynamic, respiratory, and kidney function parameters is summarized in Additional files 1 and 2 . In the studies on grades III and IV ACS, the mortality rate was $42 \%(22.2-71.4 \%)$. In grade IV ACS, there was a mortality rate of $52 \%(30-61.1 \%)$.

\section{Outcome after decompressive laparotomy in adult patients}

The mortality rate was reported in 11 of 12 studies and ranged from $22.2 \%$ to $71.4 \%$ in the individual studies; overall mortality was $49.7 \%$ (123 of 247 patients died). Of the articles that reported the mortality rate, the cause of death was described in 46 patients. Multiple organ failure was the main cause of death, followed by intestinal ischemia or necrosis. The results are summarized in Table 4. As can be seen in Fig. 4, no trend over time was observed regarding mortality rate following decompressive laparotomy. There was a trend toward a statistically significant correlation between time to decompression and mortality (grades III and IV $p=0.01$, $F=30.75, R^{2}=1$ ). However, a nonsignificant correlation between time to decompression and mortality rate was found when all adult patients were considered $\left(R^{2}=\right.$ 0.167, $F=0.803 ; p=0.065$ ) (Fig. 5).

\section{Effect of decompressive laparotomy in children} Effect of decompressive laparotomy on IAP in children In children, only one article [17] reported both baseline and postdecompression values of IAP. At the 


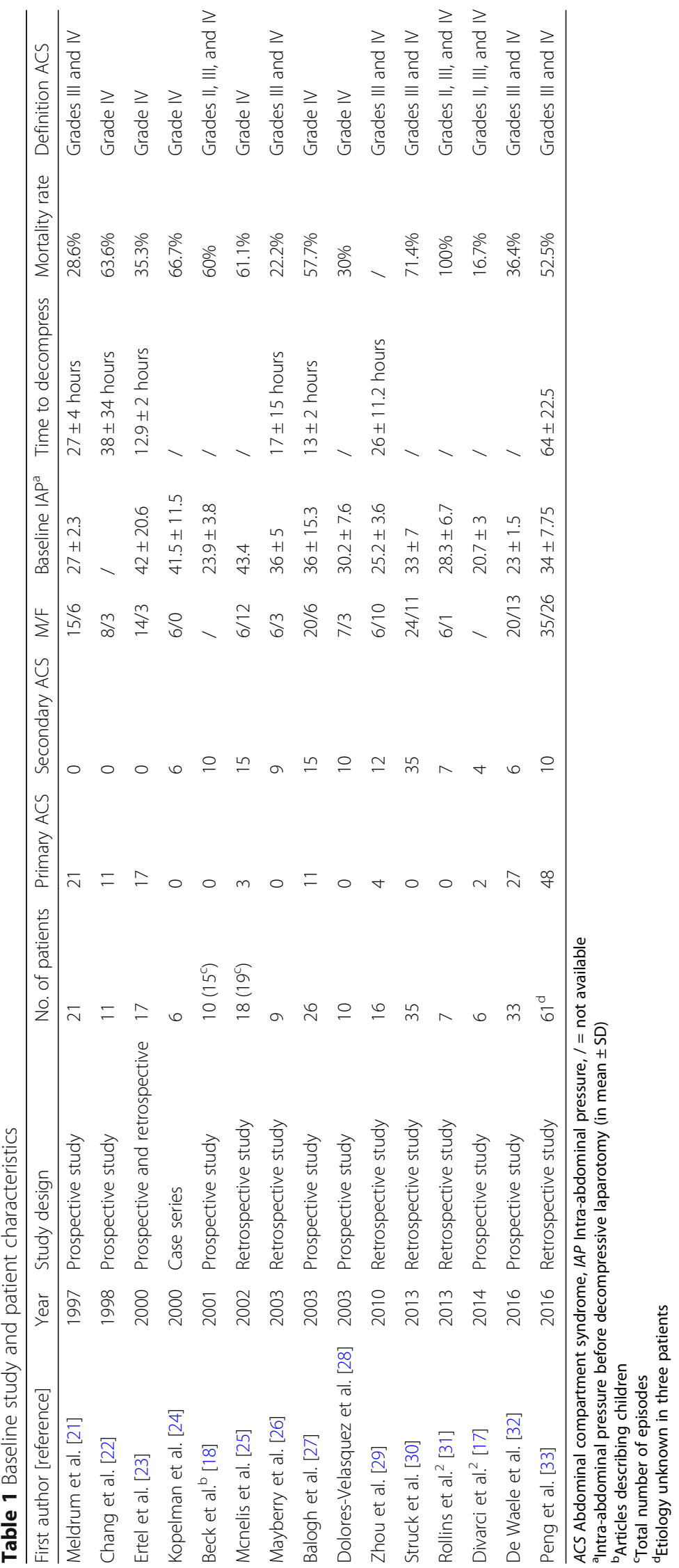




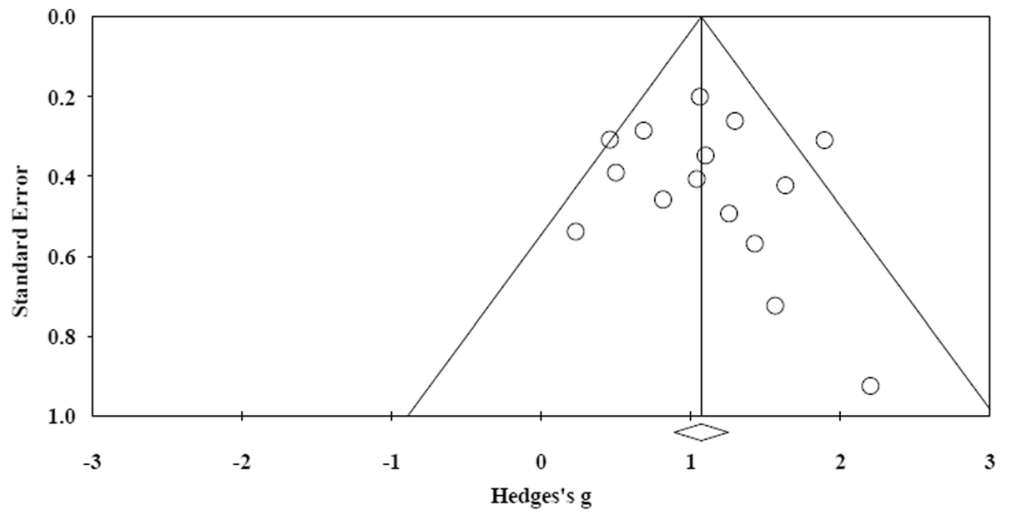

Fig. 2 Funnel plot of all articles included in this study

time of decompression, the IAP was $20.7 \mathrm{mmHg}$ and decreased to $9 \mathrm{mmHg}$ thereafter $(p<0.001 ; \mathrm{SMD}=$ 4.614) (Fig. 6).

Effect on hemodynamics, the respiratory system, and kidney function in children

The effect on HR was reported in 16 children. There was a mean baseline HR of 138.4 beats/min that increased by $4.4 \pm 1.3$ beats $/ \mathrm{min}$ after decompression $(p=$ 0.642 ; $\mathrm{SMD}=-0.156$ ). The MAP was reported in the same group and increased with $19.96 \pm 2.34 \mathrm{mmHg}$ following decompressive laparotomy $(p=0.006 ; \mathrm{SMD}=$ 1.139). One article reported the effect on CVP in seven children and showed a decrease following decompressive laparotomy from a baseline of $18 \mathrm{mmHg}$ to $11 \mathrm{mmHg}$ $(p=0.016 ; \mathrm{SMD}=1.354)$. There was only one article [18] reporting the effect on respiratory parameters in children, describing a population of ten children. The baseline P/F ratio of 125.7 increased to 449.6 following decompressive laparotomy $(p<0.001 ; \mathrm{SMD}=2.818)$. In PEEP, there was a decrease following decompression from 8.1 $\mathrm{cmH}_{2} \mathrm{O}$ to $6.3 \mathrm{cmH}_{2} \mathrm{O} \quad(p=0.129 ; \mathrm{SMD}=$ 0.671). A baseline PIP of $39.7 \mathrm{cmH}_{2} \mathrm{O}$ was reported and decreased to a postdecompression pressure of 29.8 $\mathrm{cmH}_{2} \mathrm{O} \quad(p=0.002 ; \quad \mathrm{SMD}=1.264)$. All three articles describing children reported the effect on UO, providing data on a total of 23 children. There was a baseline output of $0.52 \mathrm{ml} / \mathrm{kg} / \mathrm{h}$, ranging from 0.02 to $1.1 \mathrm{ml} / \mathrm{kg} / \mathrm{h}$, that increased to $3.4 \mathrm{ml} / \mathrm{kg} / \mathrm{h}$, varying between 2.3 and $4.0 \mathrm{ml} / \mathrm{kg} / \mathrm{h}(p<0.001 ; \mathrm{SMD}=1.363)$.

Outcome after decompressive laparotomy in children In children requiring decompressive laparotomy, the mortality rate was $60.8 \%(16.7-100 \%) ; 14$ of 23

Table 2 Methodological quality scores based on MINORS and Downs and Black

\begin{tabular}{|c|c|c|c|c|c|}
\hline First author [reference] & MINORS & $0-10$ & Downs and Black & $0-10$ & Mean \\
\hline Meldrum et al. [21] & 9 & 5.6 & 16 & 5 & 5.3 \\
\hline Chang et al. [22] & 8 & 5 & 18 & 5.6 & 5.3 \\
\hline Ertel et al. [23] & 10 & 6.3 & 23 & 7.2 & 6.8 \\
\hline Kopelman et al. [24] & 6 & 3.8 & 9 & 2.8 & 3.3 \\
\hline Beck et al. [18] & 9 & 5.6 & 17 & 5.3 & 5.5 \\
\hline Mcnelis et al. [25] & 9 & 5.6 & 20 & 6.3 & 6.7 \\
\hline Mayberry et al. [26] & 10 & 6.3 & 22 & 8.1 & 7.2 \\
\hline Balogh et al. [27] & 12 & 7.5 & 20 & 6.3 & 6.9 \\
\hline Dolores-Velasquez et al. [28] & 12 & 7.5 & 21 & 6.6 & 7.1 \\
\hline Zhou et al. [29] & 10 & 6.3 & 15 & 4.7 & 5.5 \\
\hline Struck et al. [30] & 8 & 5 & 19 & 5.9 & 5.5 \\
\hline Rollins et al. [31] & 5 & 3.1 & 13 & 4.1 & 3.6 \\
\hline Divarci et al. [17] & 10 & 6.3 & 17 & 5.3 & 5.8 \\
\hline De Waele et al. [32] & 11 & 6.9 & 21 & 6.6 & 6.8 \\
\hline Peng et al. [33] & 11 & 6.9 & 20 & 6.3 & 6.6 \\
\hline
\end{tabular}




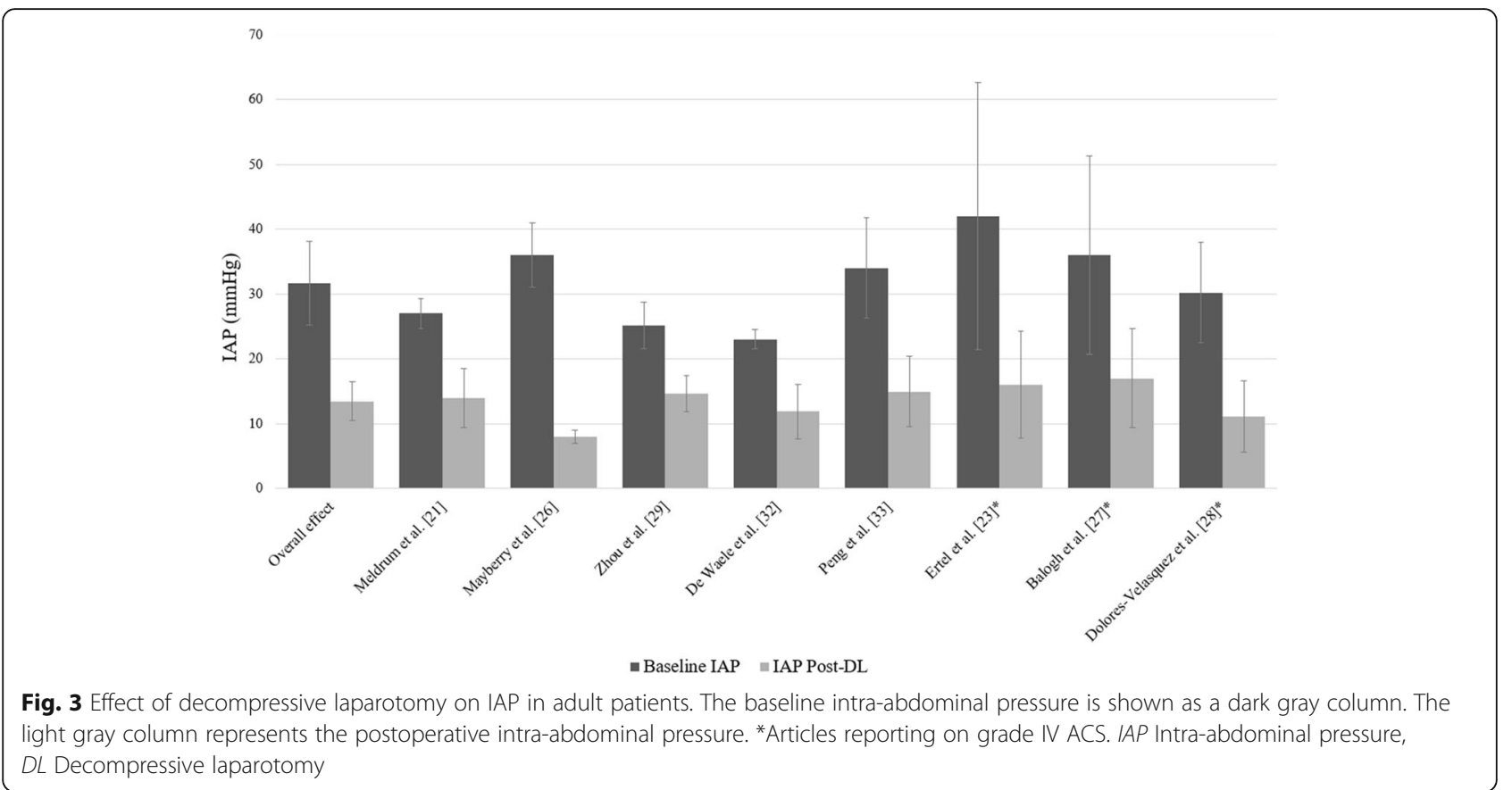

children died. The cause of death was described in 10 of the 14 children; these data can be found in Table 5.

\section{Discussion}

In this systematic review and meta-analysis, we found that decompressive laparotomy results in a significant decrease in IAP. Decompressive laparotomy also had a measurable effect on organ failure, especially on respiratory function as well as on kidney function. There was a small effect on hemodynamics, which could be seen mainly in grade IV ACS. Mortality remains high; $49.7 \%$ of adults did not survive, underlining the severity of the illness. In children, the mean mortality rate was as high as $60.8 \%$ following decompressive laparotomy.

When laparotomy is performed, most hemodynamic, respiratory, and renal parameters will improve. Therefore, the results of this meta-analysis confirm the recommendation that decompressive laparotomy should be considered when medical options fail. Clearly, though, there is still room for improvement, and new

Table 3 Effect of decompressive laparotomy on organ function in adults (all patients)

\begin{tabular}{|c|c|c|c|c|c|c|c|c|c|}
\hline \multirow[t]{2}{*}{ Variable } & \multirow{2}{*}{$\begin{array}{l}\text { No. of studies } \\
\text { reporting data } \\
\text { of variables }\end{array}$} & \multirow{2}{*}{$\begin{array}{l}\text { Mean preoperative } \\
\text { value }\end{array}$} & \multirow{2}{*}{$\begin{array}{l}\text { Mean postoperative } \\
\text { value }\end{array}$} & \multirow{2}{*}{$\begin{array}{l}\text { Mean difference } \\
\text { following } \mathrm{DL}\end{array}$} & \multicolumn{3}{|l|}{ Heterogeneity } & \multirow[t]{2}{*}{ Hedges' $g$} & \multirow[t]{2}{*}{$p$ Value } \\
\hline & & & & & Cochran's $Q$ & $d f$ & $p$ Value & & \\
\hline $\mathrm{IAP}(\mathrm{mmHg})$ & 8 & $31.7 \pm 6.4$ & $13.5 \pm 3.0$ & $-18.2 \pm 6.5$ & 56.373 & 7 & $<0.001$ & 2.222 & $<0.001$ \\
\hline HR (beats/min) & 4 & $122 \pm 10.6$ & $109 \pm 11.6$ & $-12.2 \pm 9.5$ & 7.623 & 3 & 0.054 & 0.505 & 0.040 \\
\hline MAP $(\mathrm{mmHg})$ & 5 & $82 \pm 16.3$ & $88.8 \pm 21.7$ & $+6.8 \pm 15.7$ & 40.398 & 4 & $<0.001$ & 0.173 & 0.698 \\
\hline CVP (mmHg) & 6 & $18.6 \pm 3.1$ & $14 \pm 2.9$ & $-4.6 \pm 2.3$ & 13.030 & 5 & 0.023 & 0.624 & 0.022 \\
\hline PCWP (mmHg) & 5 & $23.7 \pm 6.7$ & $17.9 \pm 3.7$ & $-5.8 \pm 5$ & 41.008 & 4 & $<0.001$ & 1.117 & 0.029 \\
\hline $\mathrm{Cl}\left(\mathrm{L} / \mathrm{min} / \mathrm{m}^{2}\right)$ & 6 & $4 \pm 1.2$ & $4.6 \pm 1.5$ & $+0.82 \pm 0.8$ & 8.145 & 5 & 0.148 & 0.569 & 0.002 \\
\hline SVRI (dyn's/cm $\left./ \mathrm{cm}^{5}\right)$ & 3 & $2009.3 \pm 364.5$ & $1484 \pm 451.2$ & $311.3 \pm 539.4$ & 42.86 & 2 & $<0.001$ & 0.534 & 0.28 \\
\hline PIP $\left(\mathrm{cmH}_{2} \mathrm{O}\right)$ & 9 & $45.5 \pm 8.7$ & $35.6 \pm 8.0$ & $-10.1 \pm 3.9$ & 22.310 & 8 & 0.004 & 1.344 & $<0.001$ \\
\hline PEEP $\left(\mathrm{cmH}_{2} \mathrm{O}\right)$ & 2 & $18.2 \pm 13.1$ & $17.4 \pm 13.2$ & $-0.9 \pm 0.1$ & 0.002 & 1 & 0.966 & 0.078 & 0.768 \\
\hline P/F ratio & 8 & $163.7 \pm 48.4$ & $234.1 \pm 55.8$ & $+70.4 \pm 49.4$ & 11.889 & 7 & 0.104 & 0.894 & $<0.001$ \\
\hline$\cup O(\mathrm{ml} / \mathrm{h})$ & 8 & $44.1 \pm 30.0$ & $139.4 \pm 109.4$ & $+95.3 \pm 105.3$ & 23.687 & 7 & 0.001 & 1.061 & $<0.001$ \\
\hline
\end{tabular}

Abbreviations: IAP Intra-abdominal pressure, $H R$ Heart rate, MAP Mean arterial pressure, CVP Central venous pressure, $P C W P$ Pulmonary capillary wedge pressure, $C I$ Cardiac index, SVRI Systemic vascular resistance index, PIP Peak inspiratory pressure, PEEP Positive end-expiratory pressure, $P / F$ ratio Ratio of partial pressure arterial oxygen and fraction of inspired oxygen, UO Urinary output 
Table 4 Cause of death in adults undergoing decompressive laparotomy

\begin{tabular}{ll}
\hline Organ failure & $\mathbf{4 1}$ \\
- Multiple organ failure & 30 \\
- Intestinal ischemia and/or necrosis & 7 \\
- Respiratory failure & 3 \\
- Cardiac failure & 1 \\
Other causes & $\mathbf{5}$ \\
- Hemorrhagic shock & 2 \\
- Septic shock & 2 \\
- Severe head injury & 1 \\
Not reported & $\mathbf{7 7}$ \\
\hline
\end{tabular}

Bold data represents the overall number of deaths following DL. A subdivision is given to specify the cause

options should be explored. It is incompletely understood which patients would benefit most from decompressive laparotomy or what is the most optimal timing for the intervention. As demonstrated in this analysis, there was a correlation between timing of decompressive laparotomy and mortality, although the correlation was weak and the clinical relevance limited. However, it is worth mentioning that in the studies in this analysis, some centers may have been reluctant to perform decompressive laparotomy, whereas others operated more rapidly, potentially leading to bias. Furthermore, we did not have individual-patient data available. When considering who would be the ideal candidates for decompressive laparotomy, it can be assumed that patients with low abdominal wall compliance are most likely to develop
ACS and would probably benefit most from decompressive laparotomy. If there were methods available to easily identify these patients, a more individualized treatment approach would be possible $[19,20]$.

Overall, organ failure is poorly defined in the reviewed articles, and many studies fail to report the true markers of organ failure. The use of the Sequential Organ Failure Assessment (SOFA) scoring system has been recommended before, in the WSACS guidelines of 2013 [1]; the two most recent studies that were included in the present review did report SOFA before as well as after decompression. However, the SOFA scoring system has its own limitations. Minor changes (in any of the organ systems) that can be beneficial in patients might be overlooked because of the broad range within gradation scores; for example, the $\mathrm{P} / \mathrm{F}$ ratio may increase from 110 to 190 , but still the SOFA score would remain unchanged.

A positive trend can be seen in the baseline IAP, where pressures over $40 \mathrm{mmHg}$ have become rare because IAP measurement is now more frequent and IAH and ACS are detected earlier. Even though there is a lower baseline IAP, the mortality rate did not improve over the years. Mortality was higher in grade IV ACS (52\%) than in grades III and IV ACS combined (42\%).

Because of the detrimental effects of ACS and the need for well-researched therapeutic options, articles need to describe not only IAP but also hemodynamic, respiratory, and renal parameters. Measuring protocols should be standardized to allow for a more complete description of data. Currently, different scoring systems and parameters are used to describe the results regarding multiple organ failure, whereas when describing

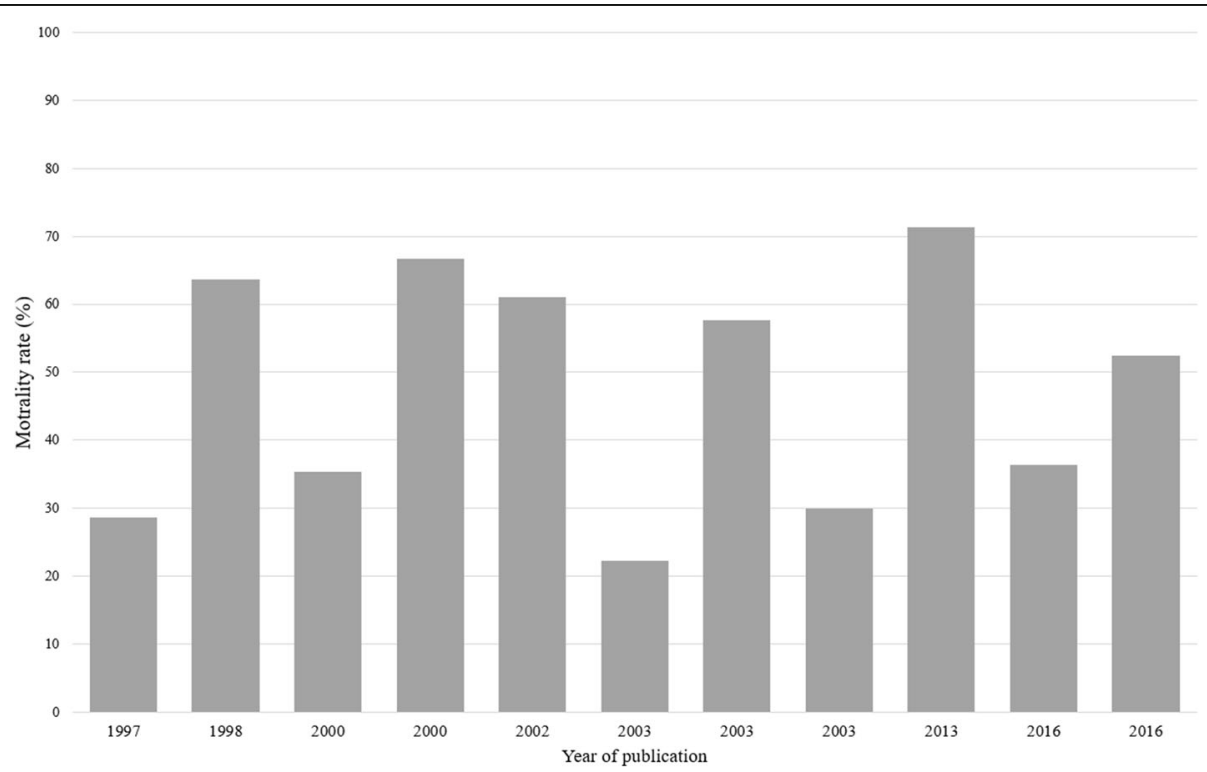

Fig. 4 Effect of decompressive laparotomy on mortality rate in adults, according to year of publication 


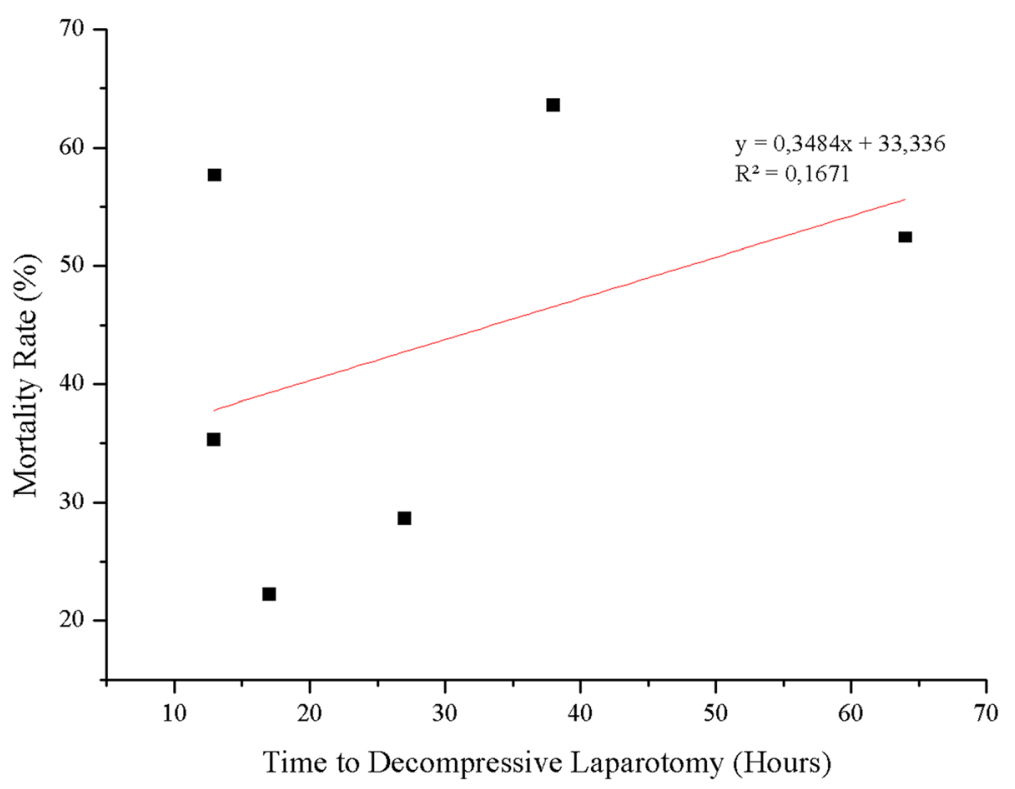

Fig. 5 Time to decompressive laparotomy and mortality rate in adults

outcome, to get a better understanding of the effect of an intervention, uniformity is key. Because mortality remains high, it is of the essence to report the cause of death when possible.

This study has several limitations. Before all the data could be analyzed, some of the data had to be converted from SEM to SD. Bessel's correction was used to correct bias in the estimation of the population variance. Nevertheless, the mean SE will often be raised in these approximations, and therefore results could vary. Furthermore, some articles reported only median and range data. The formula described by Hozo et al. to convert median values to mean and SD was used [13]. This might have affected outcomes, specifically in variance. Nonetheless, the alternative of not using these articles might be less favorable than using the estimated mean.

\section{Conclusions}

Decompressive laparotomy results in a significantly lower IAP in both adults and children with ACS. There was an improvement in hemodynamics, but these changes were not as substantial as observed in

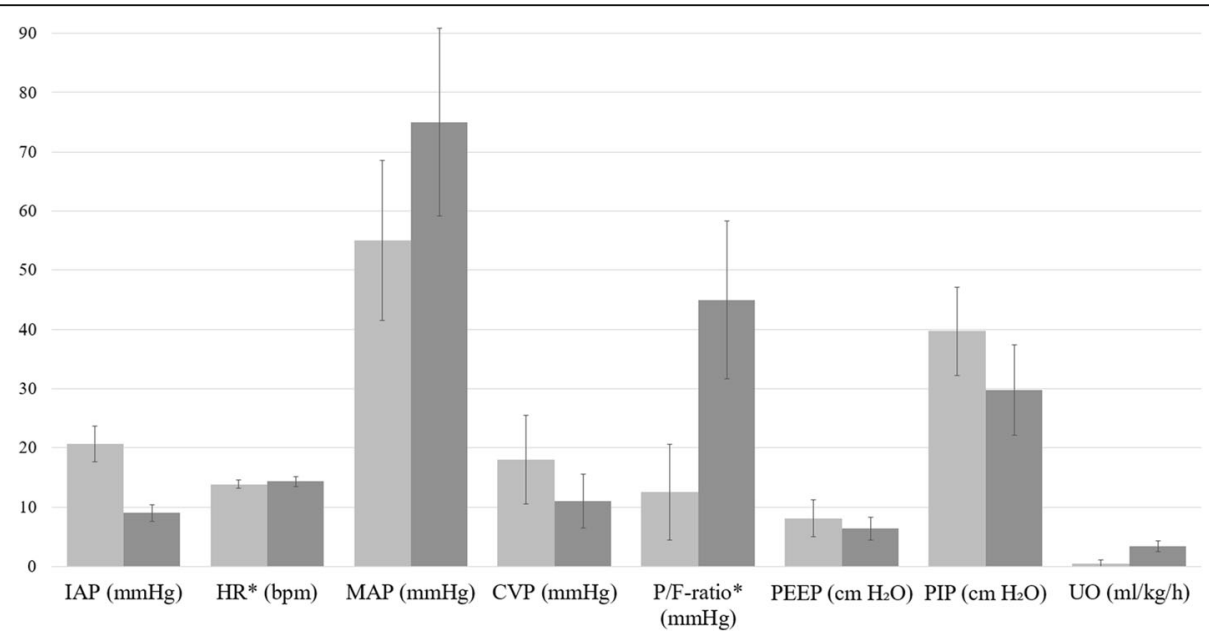

Fig. 6 Effect of decompressive laparotomy on organ function parameters in children. Preoperative IAP is shown as a light gray column. The dark gray column represents the postoperative intra-abdominal pressure. *HR and P/F ratio are shown as one-tenth of actual value. IAP Intraabdominal pressure, HR Heart rate, MAP Mean arterial pressure, CVP Central venous pressure, PIP Peak inspiratory pressure, PEEP Positive endexpiratory pressure, $P / F$ ratio Ratio of partial pressure arterial oxygen and fraction of inspired oxygen, UO Urinary output 
Table 5 Cause of death in children undergoing decompressive laparotomy

\begin{tabular}{lr}
\hline Organ failure & 3 \\
- Multiple organ failure & 2 \\
- Cardiac failure & 7 \\
Other causes & 5 \\
- Brain death whilst on ECMO & 1 \\
- Mechanical bowel obstruction & 1 \\
- Seizures resulting in brain death & 4 \\
Not reported & \\
\hline Bold data represents the overall number of deaths following DL. A subdivision \\
is given to specify the cause
\end{tabular}

respiratory and renal function parameters. Even when ACS is treated, mortality remains high because one of two adult patients died after decompressive laparotomy. Better patient selection and optimized timing of the intervention may result in better clinical outcomes in the future.

\section{Additional files}

Additional file 1: Effect of decompressive laparotomy on organ function in adults with grades III and IV ACS. IAP Intra-abdominal pressure, HR Heart rate, MAP Mean arterial pressure, CVP Central venous pressure, PCWP Pulmonary capillary wedge pressure, CI Cardiac index, PIP Peak inspiratory pressure, PEEP Positive end-expiratory pressure, $P / F$ ratio Ratio of partial pressure arterial oxygen and fraction of inspired oxygen, UO Urinary output. (XLSX $10 \mathrm{~kb}$ )

Additional file 2: Effect of decompressive laparotomy on organ function in adults with grade IV ACS. IAP Intra-abdominal pressure, HR Heart rate, MAP Mean arterial pressure, CVP Central venous pressure, PCWP Pulmonary capillary wedge pressure, CI Cardiac index, SVRI Systemic vascular resistance index, PIP Peak inspiratory pressure, PEEP Positive end-expiratory pressure, $P / F$ ratio Ratio of partial pressure arterial oxygen and fraction of inspired oxygen, UO Urinary output. (XLSX $11 \mathrm{~kb}$ )

\section{Abbreviations \\ ACS: Abdominal compartment syndrome; BP: Blood pressure; Cl: Cardiac index; CVP: Central venous pressure; HR: Heart rate; IAH: Intra-abdominal hypertension; IAP: Intra-abdominal pressure; ICU: Intensive care unit; MAP: Mean arterial pressure; MINORS: Methodological index for nonrandomized studies; P/F ratio: Ratio of partial pressure arterial oxygen and fraction of inspired oxygen; PCWP: Pulmonary capillary wedge pressure; PEEP: Positive end-expiratory pres- sure; PIP: Peak inspiratory pressure; SMD: Standardized mean difference; SOFA: Sequential Organ Failure Assessment; SVRI: Systemic vascular resistance index; UO: Urinary output; WSACS: Abdominal Compartment Society (formerly known as World Society of the Abdominal Compartment Syndrome)}

\section{Authors' contributions}

LVD and JJDW acquired, analyzed and interpreted the data. LVD and JJDW were involved in drafting and critically revising the manuscript. Both authors read and approved the final manuscript.

\section{Ethics approval and consent to participate}

Not applicable.

\section{Consent for publication}

Not applicable.

\section{Competing interests}

The authors declare that they have no competing interests.

\section{Publisher's Note}

Springer Nature remains neutral with regard to jurisdictional claims in published maps and institutional affiliations.

\section{Author details}

${ }^{1}$ Faculty of Medicine and Health Sciences, Ghent University, C. Heymanslaan 10, 9000 Ghent, Belgium. ${ }^{2}$ Department of Critical Care Medicine, Ghent

University Hospital, C. Heymanslaan 10, 9000 Ghent, Belgium.

Received: 22 February 2018 Accepted: 20 June 2018

Published online: 25 July 2018

\section{References}

1. Kirkpatrick AW, Roberts DJ, De Waele J, Jaeschke R, Malbrain MLNG, De Keulenaer B, et al. Intra-abdominal hypertension and the abdominal compartment syndrome: updated consensus definitions and clinical practice guidelines from the World Society of the Abdominal Compartment Syndrome. Intensive Care Med. 2013;39(7):1190-206.

2. Wise R, Roberts DJ, Vandervelden S, Debergh D, De Waele JJ, De Laet I, et al. Awareness and knowledge of intra-abdominal hypertension and abdominal compartment syndrome: results of an international survey. Anaesthesiol Intensive Ther. 2015;47(1):14-29.

3. Malbrain MLNG, Chiumello D, Pelosi P, Wilmer A, Brienza N, Malcangi V, et al. Prevalence of intra-abdominal hypertension in critically ill patients: a multicentre epidemiological study. Intensive Care Med. 2004;30(5):822-9.

4. Malbrain MLNG, Chiumello D, Cesana BM, Reintam Blaser A, Starkopf J, Sugrue $M$, et al. A systematic review and individual patient data metaanalysis on intraabdominal hypertension in critically ill patients: the WakeUp Project. World Initiative on Abdominal Hypertension Epidemiology, a Unifying Project (WAKE-Up!). Minerva Anestesiol. 2013;80(3):293-306.

5. Vidal MG, Weisser JR, Gonzalez F, Toro MA, Loudet C, Balasini C, et al. Incidence and clinical effects of intra-abdominal hypertension in critically ill patients. Crit Care Med. 2008;36(6):1823-31.

6. Malbrain MLNG, Chiumello D, Pelosi P, Bihari D, Innes R, Ranieri VM, et al. Incidence and prognosis of intraabdominal hypertension in a mixed population of critically ill patients: a multiple-center epidemiological study. Crit Care Med. 2005;33(2):315-22.

7. Malbrain MLNG, Cheatham ML, Kirkpatrick A, Sugrue M, Parr M, De Waele J, et al. Results from the International Conference of Experts on Intraabdominal Hypertension and Abdominal Compartment Syndrome. I. Definitions. Intensive Care Med. 2006;32(11):1722-32.

8. Cheatham ML, Malbrain MLNG, Kirkpatrick A, Sugrue M, Parr M, De Waele J, et al. Results from the International Conference of Experts on Intraabdominal Hypertension and Abdominal Compartment Syndrome. II. Recommendations. Intensive Care Med. 2007;33(6):951-62.

9. De Waele JJ, De Laet I, Malbrain MLNG. Understanding abdominal compartment syndrome. Intensive Care Med. 2016;42(6):1068-70.

10. Kirkpatrick AW, De Waele JJ, De Laet I, De Keulenaer B, D'Amours S, Björck $M$, et al. WSACS-The Abdominal Compartment Society: a society dedicated to the study of the physiology and pathophysiology of the abdominal compartment and its interactions with all organ systems. Anaesthesiol Intensive Ther. 2015;47(3):191-4.

11. De Waele JJ, Malbrain MLNG, Kirkpatrick AW. The abdominal compartment syndrome: evolving concepts and future directions. Crit Care. 2015;19:211.

12. De Waele JJ, Hoste EAJ, MLNG M. Decompressive laparotomy for abdominal compartment syndrome - a critical analysis. Crit Care. 2006;10:R51.

13. Hozo SP, Djulbegovic B, Hozo I. Estimating the mean and variance from the median, range, and the size of a sample. BMC Med Res Methodol. 2005;5:13.

14. Dersimonian R, Laird N. Meta-analysis in clinical trials. Stat Med. 1986;188: $177-88$.

15. Slim K, Nini E, Forestier D, Kwiatkowski F, Panis Y, Chipponi J. Methodological index for non-randomized studies (MINORS): development and validation of a new instrument. ANZ Journal of Surgery. 2003;73(9):712-716.

16. Downs SH, Black N. The feasibility of creating a checklist for the assessment of the methodological quality both of randomized and non-randomized studies of health care interventions. Journal of Epidemiology Community Health. 1998;52:377-384.

17. Divarci E, Karapinar B, Yalaz M, Ergun O, Celik A. Incidence and prognosis of intraabdominal hypertension and abdominal compartment syndrome in children. J Pediatr Surg. 2016;51(3):503-7. 
18. Beck R, Halberthal M, Zonis Z, Shoshani G, Hayari L, Bar-Joseph G. Abdominal compartment syndrome in children. Pediatr Crit Care Med. 2001; 2(1):51-6.

19. De Keulenaer B, Regli A, De Laet I, Roberts D, Malbrain ML. What's new in medical management strategies for raised intra-abdominal pressure: evacuating intra-abdominal contents, improving abdominal wall compliance, pharmacotherapy, and continuous negative extra-abdominal pressure. Anaesthesiol Intensive Ther. 2015;47(1):54-62.

20. Malbrain MLNG, Peeters $Y$, Wise R. The neglected role of abdominal compliance in organ-organ interactions. Crit Care. 2016;20:67.

21. Meldrum DR, Moore FA, Moore EE, Franciose RJ, Sauaia A, Burch JM Prospective characterization and selective management of the abdominal compartment syndrome. Am J Surg. 1997;174(6):663-7.

22. Chang MC, Miller PR, D'Agostino R Jr, Meredith JW. Effects of abdominal decompression on cardiopulmonary function and visceral perfusion in patients with intra-abdominal hypertension. J Trauma. 1998;44(3):440-5.

23. Ertel W, Oberholzer A, Platz A, Stocker R, Trentz O. Incidence and clinical pattern of the abdominal compartment syndrome after "damage-control" laparotomy in 311 patients with severe abdominal and/or pelvic trauma. Crit Care Med. 2000;28(6):1747-53.

24. Kopelman T, Harris C, Miller R, Arrillaga A. Abdominal compartment syndrome in patients with isolated extraperitoneal injuries. J Trauma. 2000 49(4):744-7. discussion 747-9

25. Mcnelis J, Soffer S, Marini CP, Jurkiewicz A, Ritter G, Simms HH, et al. Abdominal compartment syndrome in the surgical intensive care unit. Am Surg. 2002;68(1):18-23.

26. Mayberry JC, Welker KJ, Goldman RK, Mullins RJ. Mechanism of acute ascites formation after trauma resuscitation. Arch Surg. 2003;138(7):773-6.

27. Balogh Z, McKinley BA, Holcomb JB, Miller CC, Cocanour CS, Kozar RA, et al. Both primary and secondary abdominal compartment syndrome can be predicted early and are harbingers of multiple organ failure. J Trauma. 2003;52(5):848-61.

28. Dolores-Velásquez R, Fernando Sauri-lc LF, Sánchez-Lozada R. Efficacy of decompression treatment of abdominal compartment syndrome [in Spanish]. Gac Méd Méx. 2003;139(5):459-63.

29. Zhou J, Xu Q, Pan K, Mao C, Jin C. Effect of increased intra-abdominal pressure and decompressive laparotomy on aerated lung volume distribution. J Zhejiang Univ Sci B. 2010;11(5):378-85.

30. Struck MF, Reske AW, Schmidt T, Hilbert P, Steen M, Wrigge H. Respiratory functions of burn patients undergoing decompressive laparotomy due to secondary abdominal compartment syndrome. Burns. 2014;40(1):120-6.

31. Rollins MD, Deamorim-Filho J, Scaife ER, Hubbard A, Barnhart DC. Decompressive laparotomy for abdominal compartment syndrome in children on ECMO: effect on support and survival. J Pediatr Surg. 2013;48(7):1509-13.

32. De Waele JJ, Kimball E, Malbrain M, Nesbitt I, Cohen J, Kaloiani V, et al. Decompressive laparotomy for abdominal compartment syndrome. $\mathrm{Br} J$ Surg. 2016;103(6):709-15

33. Peng T, Dong L, Zhao X, Xiong J, Zhou F, Tao J, et al. Minimally invasive percutaneous catheter drainage versus open laparotomy with temporary closure for treatment of abdominal compartment syndrome in patients with early-stage severe acute pancreatitis. J Huazhong Univ Sci Technol. 2016;36(1):99-105.

\section{Ready to submit your research? Choose BMC and benefit from:}

- fast, convenient online submission

- thorough peer review by experienced researchers in your field

- rapid publication on acceptance

- support for research data, including large and complex data types

- gold Open Access which fosters wider collaboration and increased citations

- maximum visibility for your research: over $100 \mathrm{M}$ website views per year

At BMC, research is always in progress.

Learn more biomedcentral.com/submissions 